\title{
Peanut Component Analysis in Monozygotic Twins with Anaphylaxis to Peanut
}

Leanna-Marie Robertson ${ }^{1^{*}}$, John A Frith ${ }^{2}$, Haig Tcheurekdjian ${ }^{3}$ and Robert W Hostoffer ${ }^{4}$

${ }^{1}$ Department of Internal Medicine, University Hospitals Case Medical Center, Cleveland, Ohio, USA

${ }^{2}$ Department of Allergy/Immunology, University Hospitals Richmond Medical Center, Richmond Heights, Ohio, USA

${ }^{3}$ Allergy/Immunology Associates Inc., Mayfield Heights, Ohio, USA

"Corresponding author: Leanna-Marie Robertson, Department of Internal Medicine, University Hospitals Case Medical Center, Cleveland, Ohio, USA, Tel: + (317) 502-7164; E-mail: Leanna-Marie.Robertson@UHhospitals.org

Received date: April 26, 2016; Accepted date: May 26, 2016; Published date: May 30, 2016

Copyright: (c) 2016 Robertson LM, et al. This is an open-access article distributed under the terms of the Creative Commons Attribution License, which permits unrestricted use, distribution, and reproduction in any medium, provided the original author and source are credited.

\section{Case Report}

Monozygotic twin studies can be used to show heritability in many disorders. Studies have elucidated the concordance of food allergies in these types of twins. Peanut allergies in this population have only been explored using questionnaires without the documentation of the IgE mediated reaction, the monozygotic nature of the twins, the course of the reaction and subsequent outcome. We report a case of documented monozygotic twins with anaphylaxis to peanut and their eventual different response to peanut component analysis.

The patients are 2-year-old healthy Caucasian monozygotic twin males without any active or prior medical problems or diagnoses (who will be referred to by twin A and twin B). Both parents have allergic rhinitis triggered by cat hair. Additionally, the twins' mother has mild, intermittent asthma for which she uses a rescue inhaler sparingly. Neither the father nor the mother has any known food allergies. Both twin A and twin B were simultaneously having peanut butter introduced into their diet for the first time. The boys were in the same state of health at this time- without viral illness. Within 10 minutes of ingesting approximately 1 teaspoon of peanut butter, twin A developed itching and hives. On route to the Emergency Department (ED), twin A then developed lip swelling. Twin A had no cough or shortness of breath. In the ED, twin A's symptoms were immediately treated with intramuscular epinephrine, intravenous steroids and an H1-receptor antagonist. Twin A's lab work in the ED revealed a peanut IgE level of $2.1 \mathrm{kU}_{\mathrm{A}} / \mathrm{L}$. Twin A was later seen in an outpatient clinic for follow up where additional lab work revealed a peanut $\operatorname{IgE}$ level of $2.27 \mathrm{kU} / \mathrm{L}$, Ara h 2 level of $0.25 \mathrm{kU}_{\mathrm{A}} / \mathrm{L}$ and Ara h 1, 3, 8, 9 levels all $<0.1 \mathrm{kU}_{\mathrm{A}} / \mathrm{L}$.

Twin B developed itching, hives, flushing, lacrimation, cough, face/lip/tongue swelling and tachycardia within 10 minutes of consuming the same quantity of peanut butter. In the ED, twin B's symptoms were treated identically to twin A. Twin B's lab work in the ED revealed peanut IgE level of $26.2 \mathrm{kU} / \mathrm{L}$. Twin $\mathrm{B}$ also had additional lab work done later in the outpatient setting which revealed peanut $\mathrm{IgE}$ level of $7.30 \mathrm{kU}_{\mathrm{A}} / \mathrm{L}$, Ara h 2 level of $1.49 \mathrm{kU}_{\mathrm{A}} / \mathrm{L}$, Ara h 9 level of 0.64 $\mathrm{kU}_{\mathrm{A}} / \mathrm{L}$ and Ara h 1, 3, 8 levels all $<0.1 \mathrm{kU}_{\mathrm{A}} / \mathrm{L}$.

Monozygotic twins provide a valuable opportunity to study specific diseases. Their genetic makeups mirror each other on a cellular basis and differences in presentation of disease are more easily honed in on with a mostly common genotype as the background. Peanut allergy (PA) is known to have a heritable component with specific associations found between PA and HLA-DR and -DQ alleles [1]. In this clinical scenario, one twin reacted to the same allergen with only cutaneous signs (hives, itching, angioedema) while his identical twin presented with anaphylaxis involving the lower respiratory tract (cough), cardiovascular system (tachycardia) and ocular symptoms (tearing) in addition to skin manifestations (itching, hives, flushing).

The analysis of IgE to peanut components has been shown to be clinically helpful and possibly more accurate than IgE to whole peanut [2]. Ara h 1, Ara h 2 and Ara h 3 are considered the major peanut allergens [3]. IgE to Ara h 2 has been shown to be the best overall diagnostic test with the most specificity and the best positive predictive value [2]. The component testing of this identical twin pair showed that they were different in their antigen recognition.

Sicherer et al. detailed a discussion of twins in which he described the heritability of peanut allergy [4]. He and his colleagues determined twin zygosity by questionnaire of the twins' physician, their parental surrogates or both [4]. The conclusion of their twin study showed that $64.3 \%$ of monozygotic pairs were concordant for peanut allergy whereas only $6.8 \%$ of dizygotic pairs showed concordance [4]. Hong et al. then used the findings of Sicherer et al. as a building block upon which their genome-wide association studies have shown the possibility that the HLA-DR and -DQ gene region likely poses the single greatest genetic risk for peanut allergy [5]. Further, Liem et al. have compared the concordance rates of Sicherer et al. to their studies of prevalence among siblings and used similar questionnaire method to obtain certain information and ultimately show that the risk of peanut allergy was markedly increased in siblings of a peanut-allergic child [6].

The aforementioned shows that this landmark paper by Sicherer et al. has laid the foundation upon which several other hereditary studies regarding twins have been built. The determination for inclusion of analysis of the data was made by Sicherer and the other authors based on their interpretation of adequate histories and zygosity information. As can be expected by this questionnaire format with a basis of reliance on recall, the accuracy of the zygosity of the twins is a weakness of this study that the authors themselves acknowledge. In this case, we were able to assure monozygosity via ultrasound imaging during gestation (Figure 1). Additionally, this case shows that there can be a difference in protein response between the members of an identical twin pair.

Here we report a pair of identical twins responding to the same allergen differently both from a clinical and antigen processing perspective. This information is important for physicians to be aware of as it shows that monozygotic twins while genetically identical can have very different reactions to the same allergen. Furthermore, this case highlights an opportunity for future work delineating the possible mechanisms involved in discordant monozygotic twin responses to the same allergen. 
Citation: $\quad$ Robertson LM, Frith JA, Tcheurekdjian H, Hostoffer RW (2016) Peanut Component Analysis in Monozygotic Twins with Anaphylaxis to Peanut. J Allergy Ther 7: 234. doi:10.4172/2155-6121.1000234

Page 2 of 2

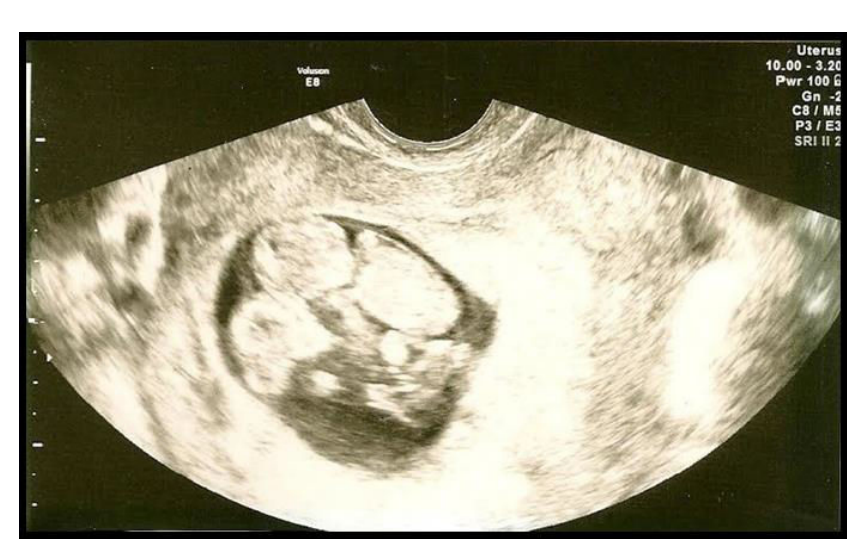

Figure 1: Ultrasound imaging during gestation

\section{References}

1. Helmer JA, Phillips EJ, Mallal SA, Kendall PL (2015) The evolving story of human leukocyte antigen and the immunogenetics of peanut allergy. Ann Allergy Asthma Immunol 115: 471-476.

2. Lieberman JA, Glaumann S, Batelson S, Borres MP, Sampson HA, et al. (2013) The utility of peanut components in the diagnosis of IgE-mediated peanut allergy among distinct populations. J Allergy Clin Immunol Pract 1: 75-82.

3. Otsu K, Dreskin SC (2011) Peanut allergy: An evolving clinical challenge. Discov Med 12: 319-328.

4. Sicherer SH, Furlong TJ, Maes HH, Desnick RJ, Sampson HA, et al. (2000) Genetics of peanut allergy: A twin study. J Allergy Clin Immunol 106: 53-56.

5. Hong X, Hao K, Ladd-Acosta C, Hansen KD, Tsai HJ, et al. (2015) Genome-wide association study identifies peanut allergy-specific loci and evidence of epigenetic mediation in US children. Nat Commun 6: 6304.

6. Liem JJ, Huq S, Kozyrskyj AL, Becker AB (2008) Should Younger Siblings of Peanut-Allergic Children Be Assessed by an Allergist before Being Fed Peanut? Allergy Asthma Clin Immunol 4: 144-149. 